\title{
Alternative patch repair materials for rebar corrosion damage
}

\author{
Primesh Jassa ${ }^{1, *}$, Hans Beushausen ${ }^{1}$, and Ines Tchetgnia Ngassam $^{1}$ \\ ${ }^{1}$ Concrete research and structural integrity research unit (CoMSIRU), Department of Civil Engineering, University of Cape \\ Town (UCT), South Africa.
}

\begin{abstract}
One of the most common methods adopted in the rehabilitation of corrosion-damaged concrete is the patch repair procedure. However, in practice this method has shown to often be unreliable as a consequence of the widespread occurrence of shrinkage induced cracking and poor substrate-patch adhesion leading to debonding of the patch repair. From a practical point of view, such failed repair systems essentially restore the repaired concrete back to a deteriorated state. There is a common belief that repairing concrete with specialised proprietary repair materials would guarantee durability. However, the widespread premature failure of patch repairs conducted using such materials has proven the contrary. This paper presents an understanding of the materials and issues concerning the durability and serviceability of concrete patch repairs, with the aim of identifying alternative non-structural patch repair materials for the effective repair of corrosiondamaged concrete structures. The potential patch repair materials researched were polymer-cement concrete (copolymer of vinyl acetate and ethylene with 5\% cement replacement) and $60 \%, 80 \%$ and $100 \%$ fly ash (FA) mortar. Patch repairs were conducted on substrate moulds to test application and observe cracking/debonding occurrence. Furthermore, compressive strength, durability index, accelerated drying shrinkage, restrained shrinkage, workability and scanning electron microscopy (SEM) tests were conducted to determine the properties of the materials developed with reference to performance requirements of durable concrete repairs. It was concluded that the $60 \% \mathrm{FA}$ and polymer-cement concrete repair materials had the best overall performance. This research established that innovative alternative repair materials such as a $60 \%$ FA or polymer-cement concrete material, can be developed for non-structural patch repairs with improved long-term performance relative to conventional materials.
\end{abstract}

\section{Introduction}

Steel corrosion is of major concern in civil engineering due to its widespread occurrence and associated effects of concrete cracking, delamination and spalling. Early failure of concrete due to reinforcement corrosion is an important issue since the rehabilitation of deteriorating infrastructure is a difficult task that usually has massive cost implications. One of the most widely applied solutions for the repair of corrosion-damaged reinforced concrete is the patch repair method. However, the lack of durability of these concrete patch repairs is very common the world over.

A comprehensive investigation on 230 concrete structures in Europe called the ConRepNet Report concluded that up to $50 \%$ of all concrete repairs had failed prematurely [1]. Furthermore, the report concluded that $75 \%$ of all repairs failed within the first 10 years of service, refer to Fig. 1. This failure rate occurs despite the fact that numerous improvements in materials and methods have been developed. In practice, the continuation of corrosion in the adjacent substrate concrete, shrinkage induced cracking and debonding of the patch repair is widespread. These mechanisms fundamentally return the concrete integrity back to a deteriorated state.

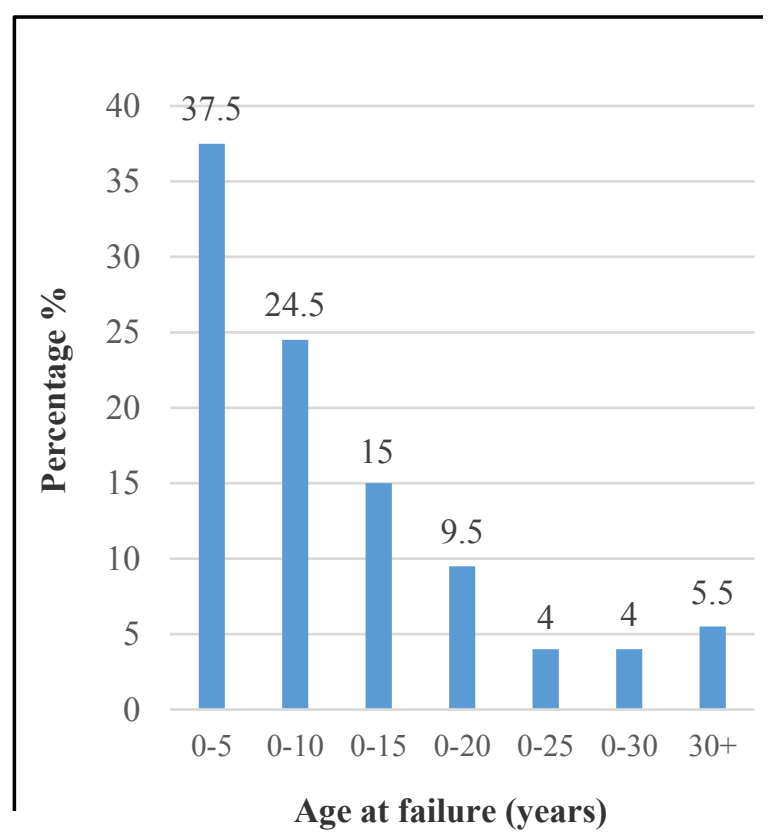

Fig. 1. Age of concrete repair at failure [1]

There are a multitude of underlying reasons for these failures including a lack of technical knowledge, application of substandard construction methods, poor substrate preparation, incorrect selection of repair

\footnotetext{
* Corresponding author: primeshjassa@gmail.com
} 
materials, insufficient curing, time-dependent material properties, wrong diagnosis and severe environmental conditions. However, poor workmanship and differential shrinkage between the substrate and patch have been identified by [2] as the chief inhibiting factors for the durability and service life performance of patch repair systems. The performance of concrete repairs can be improved by essentially adopting a correct and complete repair programme. A successful, non-structural patch repair would be one where:

- The repair material does not delaminate from the substrate concrete.

- Cracking is limited, and any cracking of the repair material does not impair repair performance with respect to delamination and corrosion.

- Corrosion is prevented in areas around the patch repair.

- Application of the repair material is easy and practical.

- The repair material is aesthetically acceptable.

It must be understood that a patch repair material will only exhibit good long-term durability if a complete repair procedure is implemented correctly. To achieve the above performance requirements, a complete repair process would include the following:

- Treatment of corrosion damaged steel in the patch repair area by cleaning and coating or replacement in severe corrosion cases.

- Substrate surface preparation by thorough cleaning and surface roughening.

- Installation of sacrificial anodes to prevent future corrosion, particularly in the case of chloride contaminated concrete.

- Applying a surface coating once the patch repair has been completed to provide further protection and restore the aesthetics of the structure.

If all corroded steel is adequately treated and the underlying cause of corrosion addressed, then the only requirement for a complete, non-structural patch repair on carbonation damaged concrete would be to fill in the cavity initially created by removing defective concrete. For non-structural repairs on carbonation-damaged structures, in isolation to the integrity of the adjacent substrate, the basic purpose of the fill material selected would be to simply restore the serviceability (aesthetics) of the repaired element. Fundamentally, this can be achieved with any material, which does not specifically need to be a specialised repair mortar. However, in the case of chloride ion induced corrosion, any nonstructural patch repair also needs to limit the ingress of aggressive media into the repair. The material needs to have the added property of being impermeable to chloride ions and moisture.

The use of highly specialised commercially available repair mortars for non-structural patch repairs is widespread in the repair industry. There is a common misconception that repairing damaged concrete with such materials would guarantee durability. However, widespread use of specialised commercially available repair mortars for the patch repair of deteriorated concrete has shown no significant improvement in the long-term durability of patch repairs. Fundamentally, this is a consequence of the limitations of using cementitious-based repair materials and the lack of understanding of the critical material properties actually required of patch repair materials. The use of specialised repair mortars for patch repairs is in many cases probably not necessary.

This is because the properties exhibited by these mortars, such as high compressive strength and elastic modulus are not required for non-structural patch repairs. Furthermore, high mechanical performance of repair mortars may even result in a lack of performance with regards to cracking $[3,4]$. An ideal patch repair material needs to meet the following performance requirements:

- Crack resistance

- Adequate bonding

- Low permeability

- Adequate workability and consistency

- Reasonable setting time and

- Acceptable aesthetics.

A seemingly, from a conventional point of view, substandard material that meets these requirements has the potential to outlast specialised cementitious repair mortars in non-structural patch repair applications. This research aimed at identifying such alternative materials for the durable and non-structural patch repair of corrosion-damaged concrete. The experimental regime adopted was aimed at establishing the properties of the repair materials developed in this study with reference to the performance requirements.

\section{Experimental methodology}

An overview of the different phases and experimental investigations conducted in this research project are summarised in Fig. 2. The research presented in this paper was divided into a number of phases. In phase one a literature review was conducted to develop a framework to understand the underlying principles and issues concerning the research topic. Phase two was directed towards identifying alternative materials for non-structural patch repairs by specifying the performance properties required of such materials and reviewing literature that looked into the development of new concrete materials including non-cementitious ones. Phase three delved into the development and optimisation of the mix designs for the FA and polymer materials selected for use in non-structural patch repairs. This was necessary since there was no existing literature (at the time of this study) on the use of these materials for patch repairs particularly, for the polymer materials. Phase four of the research project was concentrated on experimentally determining the performance of the FA and polymer materials in non-structural patch repairs relative to a control. Lastly, phase 4 and 5 of the research project looked into the analysis of the experimental results in order to draw out conclusions and make recommendations for future studies based on the theme of this research. 


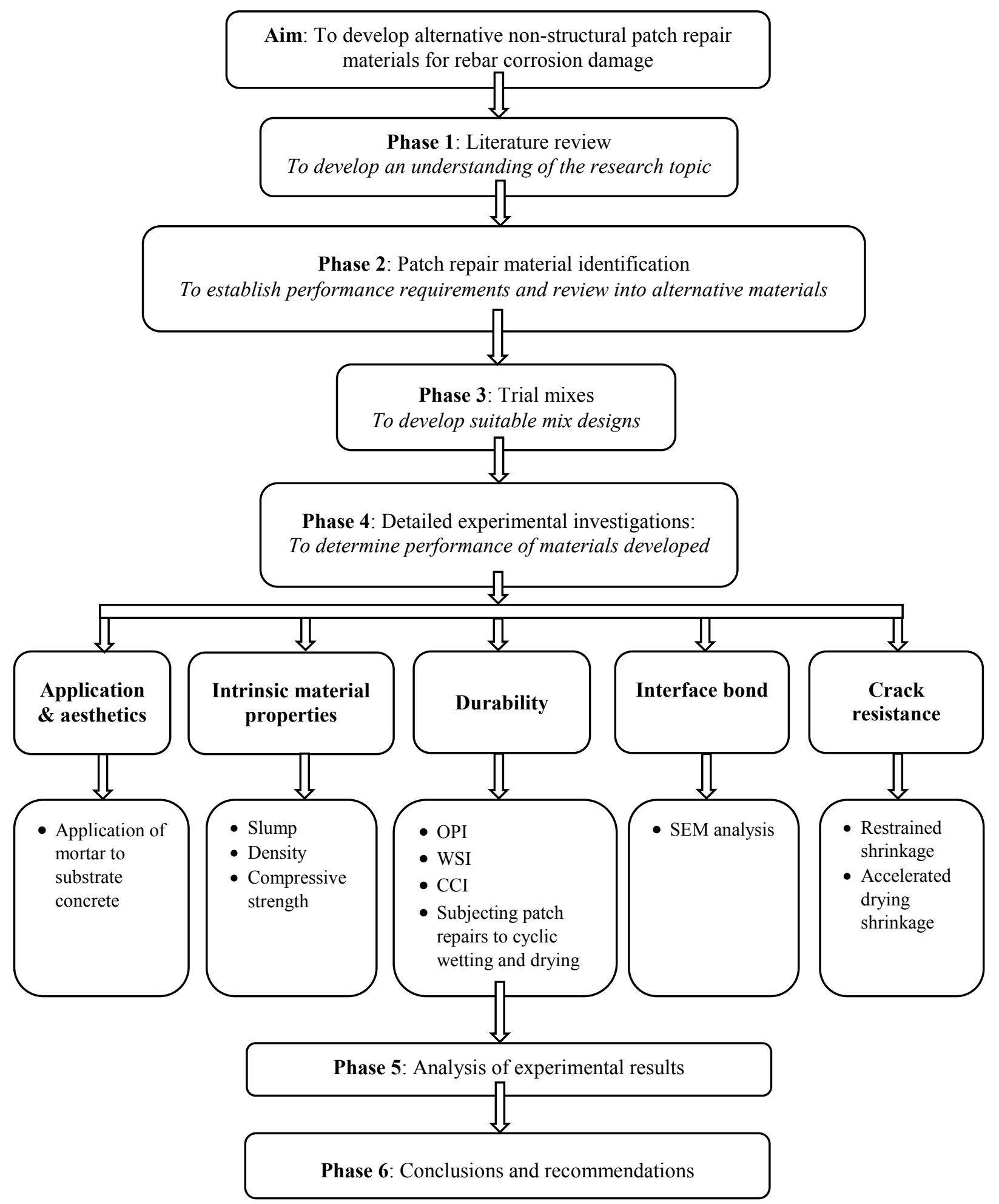

Fig. 2. Flow chart illustrating structure of research and experimental programme

\subsection{Application and aesthetics}

With respect to the theme of this research project it was paramount to experimentally investigate into the ease and process of application of the selected repair materials to non-structural patch repairs as well as the aesthetics of a repaired element. These tests were essential to determine the practicality of using the repair materials developed. To test the application of the new repair materials on patch repairs, custom-made concrete moulds were manufactured to mimic a typical substrate. A characteristic substrate requiring a patch repair would have all deteriorated concrete removed from the vicinity of the corroded steel, creating a cavity with exposed steel. Therefore, to manufacture concrete elements representative of such substrates, special concrete moulds were developed to make concrete slabs as shown in Fig. 3. Two patch repair substrates were cast for each of the five different repair materials. One was left for 
observation under room conditions and the other was used for cyclic wetting and drying conditioning. Whilst applying the patch repair material to the substrate moulds, the process and ease of application of the repair material was determined.

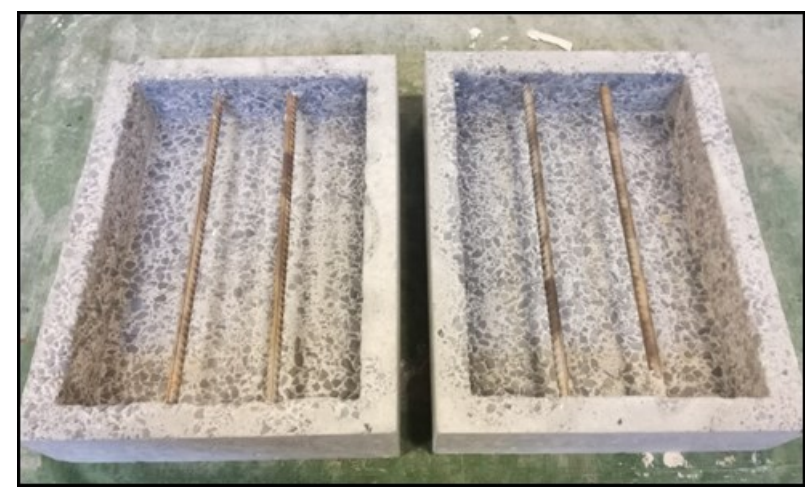

Fig. 3. Custom sandblasted concrete substrate moulds

\subsection{Intrinsic material properties}

Workability, density and compressive strength tests were conducted on the different patch repairs to determine the intrinsic material properties.

To establish the workability and consistency of the repair materials selected, the slump test was conducted. The test was conducted on the different repair materials in accordance to SANS 5862-1.

Compressive strength tests for each repair material were conducted at 7,14, 28 and 60 days to monitor the strength development of the different materials. The testing was done with reference to SANS 5863 (2006) using an Amsler compression test machine.

In order to establish the density of the different repair materials developed, $100 \times 100 \times 100 \mathrm{~mm}$ cubes were cast. The dimensions and weight of these cubes were measured and used to calculate the density of the repair materials.

\subsection{Durability}

\subsubsection{Cyclic wetting and drying}

One patch repaired substrate mould for each of the five different repair materials was left for observation under normal room conditions. The development of any debonding and/or surface cracking on the moulds was observed for 56 days (8 weeks). Additionally, one repaired substrate mould for each of the five different repair materials was subjected to cyclic wetting and drying conditions. Cyclic testing was done to identify the effect of cyclic conditioning on the repaired element with respect to cracking and/or debonding (i.e. durability). The substrate moulds were left for 24 hours in a controlled environmental room at $30 \pm 2.0^{\circ} \mathrm{C}$ and a relative humidity of $30 \pm 4 \%$ for the drying cycle. The moulds were then removed and placed for 24 hours in a water bath at $22 \pm 2.0^{\circ} \mathrm{C}$ for the wetting cycle. After 24 hours, the moulds were removed from the water bath and surface dried with a paper towel. The drying cycle was then repeated. The wetting and drying cycles were conducted for 56 days i.e. 28 cycles.

\subsubsection{Durability Index tests}

Durability Index tests were conducted on the repair materials and these were conducted as specified in the Durability Index Testing Procedure Manual developed at UCT [5]. Durability index testing involves three important tests namely: Oxygen Permeability Index (OPI) and Water Sorptivity Index (WSI) tests.

\subsection{Interface bond}

Microscopic analysis was conducted on the different repair materials to investigate into the bond characteristics between the patch repair material and the substrate concrete. Material specimens were cored from the patch repair moulds. $70 \pm 2 \mathrm{~mm}$ diameter cores were taken and these were cut into $8 \pm 2 \mathrm{~mm}$ discs. These specimen discs were then specially prepared for scanning electron microscopy (SEM) testing. The prepared samples are shown in Fig. 4.

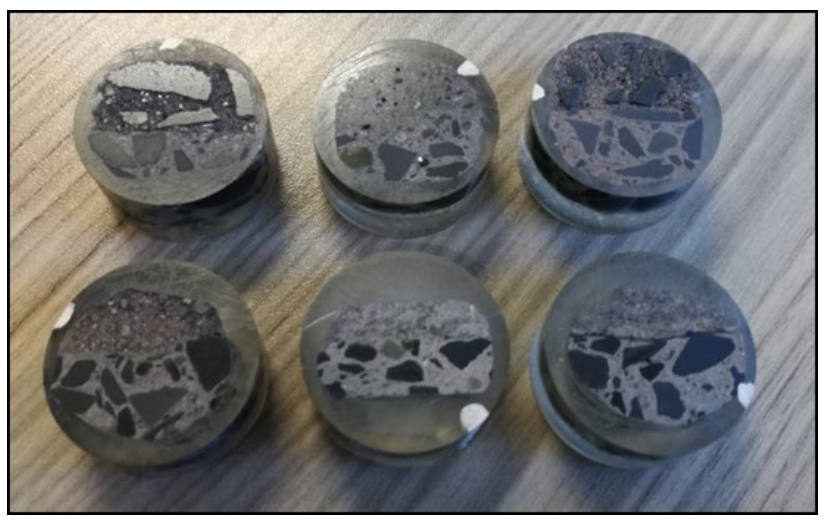

Fig. 4. Prepared samples for SEM analysis

\subsection{Crack resistance}

\subsubsection{Restrained shrinkage - ring test}

The ring test was conducted to determine the cracking potential of the different repair materials studied in this dissertation. The ASTM C1581 standard was followed in conducting the ring tests however, a crack meter was used for measuring crack width instead of the recommended strain gauge.

\subsubsection{Accelerated drying shrinkage test}

In order to determine the shrinkage potential of the different repair materials, accelerated drying shrinkage tests were conducted on $100 \times 100 \times 200 \mathrm{~mm}$ prisms in accordance to SANS 6085 (2006). 


\section{Mix designs developed}

Table 1 outlines the mix designs used for the detailed experimental investigations for the FA and polymercement concrete repair materials based on the results of the trial mixes. These mixes were used for all the detailed experimental investigations. The mix design adopted for the control repair mortar was selected with reference to the works of [6] and [7] where it was identified that such a mix design generally falls within the range of normal concrete mortars that may be used in overlay repairs.

\section{Results}

The key experimental results of the research study are summarised in Table 2 .

Table 1: Repair material mix designs

\begin{tabular}{|c|c|c|c|c|c|}
\hline Material & $\begin{array}{c}100 \% \\
\text { FA mix }\end{array}$ & $\begin{array}{c}80 \% \text { FA } \\
\text { mix }\end{array}$ & $\begin{array}{c}60 \% \text { FA } \\
\text { mix }\end{array}$ & $\begin{array}{l}\text { Polymer-cement } \\
\text { concrete mix } \\
\text { with } 5 \% \text { cement }\end{array}$ & Control \\
\hline Fly ash $\left(\mathrm{kg} / \mathrm{m}^{3}\right)$ & 432 & 388 & 299 & - & - \\
\hline Cement - CEM I $52.5 \mathrm{~N}\left(\mathrm{~kg} / \mathrm{m}^{3}\right)$ & - & 97 & 200 & - & - \\
\hline Cement - CEM II $42.5 \mathrm{~N}\left(\mathrm{~kg} / \mathrm{m}^{3}\right)$ & - & - & - & 8 ( $5 \%$ by mass $)$ & 540 \\
\hline Polymer binder $\left(\mathrm{kg} / \mathrm{m}^{3}\right)$ & - & - & - & 153 & - \\
\hline Calcium hydroxide (by mass of fly ash) & $2.5 \%$ & 0 & 0 & - & - \\
\hline Sodium hydroxide (by mass of fly ash) & $2.5 \%$ & 0 & 0 & - & - \\
\hline Water $\left(\mathrm{kg} / \mathrm{m}^{3}\right)$ & 194 & 218 & 225 & 97 & 243 \\
\hline Fine aggregate - dune sand $\left(\mathrm{kg} / \mathrm{m}^{3}\right)$ & 1545 & 1455 & 1455 & 703 & 1462 \\
\hline Coarse aggregate $-13 \mathrm{~mm}$ greywacke $\left(\mathrm{kg} / \mathrm{m}^{3}\right)$ & - & - & - & 1055 & - \\
\hline Superplasticizer $\left(\mathrm{ml} / \mathrm{m}^{3}\right)$ & 238 & 0 & 0 & - & 66 \\
\hline $\mathrm{w} / \mathrm{b}$ ratio & 0.45 & 0.45 & 0.45 & 0.60 & 0.45 \\
\hline Average density $\left(\mathrm{kg} / \mathrm{m}^{3}\right)$ & 1901 & 2106 & 2121 & 2137 & 2132 \\
\hline 28-day compressive strength (MPa) & 1.5 & 8.0 & 17.4 & 1.4 & 45.1 \\
\hline
\end{tabular}

Table 2: Summary of key quantitative experimental results

\begin{tabular}{|c|c|c|c|c|c|}
\hline Test & $\begin{array}{c}100 \% \\
\text { FA }\end{array}$ & $80 \%$ FA & $60 \%$ FA & $\begin{array}{c}\text { Polymer-cement } \\
\text { concrete }\end{array}$ & Control \\
\hline Slump (mm) & 45 & 65 & 25 & 260 & 35 \\
\hline 60-day compressive strength (MPa) & 1.6 & 14.2 & 21.5 & 1.8 & 43.5 \\
\hline Density $\left(\mathrm{kg} / \mathrm{m}^{3}\right)$ & 1872 & 2102 & 2132 & 2137 & 2137 \\
\hline OPI & 8.72 & 9.34 & 9.91 & 10.15 & 10.04 \\
\hline Permeability coefficient $\mathrm{k}(\mathrm{m} / \mathrm{s})$ & $1.93 \mathrm{E}-09$ & 4.53E-10 & $1.24 \mathrm{E}-10$ & 7.07E-11 & $9.12 \mathrm{E}-11$ \\
\hline Sorptivity $\left(\mathrm{mm} / \mathrm{hr}^{0.5}\right)$ & 42.4 & 13.2 & 10.0 & 11.4 & 5.2 \\
\hline Porosity (\%) & 17.5 & 21.8 & 19.9 & 2.5 & 14.5 \\
\hline Restrained shrinkage (ring) test crack age (days) & 24 & 13 & 10 & $\begin{array}{l}\text { No cracks after } 70 \\
\text { days }\end{array}$ & 7 \\
\hline Accelerated drying shrinkage $(\mu-\varepsilon)$ & 573 & 343 & 293 & 1517 & 415 \\
\hline
\end{tabular}




\section{Discussion of results}

The FA repair material results generally show that a higher percentage of FA led to significant deterioration in the overall performance of the repair material. The application of the FA mixes to substrate concrete was straightforward since the mixes had similar consistencies to the control repair mortar. Although innovative and resource sensitive, the $100 \% \mathrm{FA}$ repair material exhibited poor durability and very low strength properties, as expected. This was likely due to the adoption of an unsuitable mix design and the ambient curing of the alkali activated fly ash rather than elevated temperature curing. Furthermore, a 100\% FA mix would inherently have low strength since FA is a pozzolanic material with little cementitious properties on its own. Nevertheless, this mix was subjected to all the tests in order to provide a reference for comparison of the results relative to the other repair materials. Moreover, based on the theme of this research is was important to test the change in patch repair performance with the use of a very low strength repair material in order to analyse combined relationships between strength, durability and crack resistance.

The $100 \%$ FA material exhibited good crack resistance since deformations could be easily accommodated within the matrix due to the very low strength. However, the bonding performance of this material was very poor. Upon analysis, the $100 \%$ FA specimens subjected to both room conditions and cyclic conditioning were found to completely separate from the substrate concrete. Furthermore, a very low compressive strength of 1.6 MPa (60-day), OPI of 8.72 and high sorptivity of $42.4 \mathrm{~mm} / \mathrm{hr}^{0.5}$ resulted in this material being very brittle and absorptive. Additionally, accelerated drying shrinkage of $573 \mu-\varepsilon$ was also obtained. As a consequence of these results the $100 \%$ FA material developed in this study would not be suitable for any practical application to patch repairs due to its very low strength and poor bonding performance.

The $80 \%$ FA repair material displayed borderline performance properties. The restrained shrinkage performance of this material was good relative to the control. Restrained shrinkage rings cracked after 13 days, which was almost double the time it took for the control rings to crack. Furthermore, the strength performance of this material was much better relative to the $100 \%$ FA repair material. The $80 \%$ FA material exhibited compressive strengths of up to $14 \mathrm{MPa}$ after 60 days. However, the poor durability index test results meant that this material will not allow for any durable concrete repair application. Moreover, the $80 \%$ FA specimens subjected to cyclic conditioning showed clear signs of debonding and hence the bonding performance of this material was found to be unsatisfactory. It can be identified that both the $80 \%$ FA and $100 \%$ FA repair materials would fail to significantly improve the durability of non-structural patch repairs particularly in aggressive environments. The strength and bonding performance of the $80 \% \mathrm{FA}$ and $100 \%$ FA materials could be improved by using certain admixtures (such as the polymer used in this study) which can be investigated in future studies.

In contrast, the $60 \% \mathrm{FA}$ repair material exhibited satisfactory strength and durability performance. The compressive strength of this material was found to be up to $21 \mathrm{MPa}$ after 60 days. This material exhibited the lowest accelerated drying shrinkage relative to all the other repair materials analysed. Furthermore, the $60 \%$ FA specimens subjected to cyclic conditioning exhibited good performance with respect to adhesion with no clear signs of debonding. The trend observed here was likely due to the cement content ( $40 \%$ by mass) that allowed for an improved matrix formation and thus improved penetrability and strength properties. It was found that the $60 \%$ FA repair material developed in this study has good potential to be effectively applied to non-structural patch repairs.

The polymer-cement concrete displayed very good performance with respect to crack resistance and durability (low penetrability and sorptivity). The polymer-cement concrete shrinkage rings showed no visible cracks even after 70 days of observation. This was despite the fact that the material exhibited high shrinkage (which is commonly perceived as bad) when tested under accelerated drying conditions. A high accelerated drying shrinkage of $1517 \mu-\varepsilon$ was exhibited by this material since it continuously contracted due to the slow setting and water loss process. However, high shrinkage had no overall negative effect on crack resistance since the shrinkage was offset by the plastic nature of the polymer-cement concrete. Furthermore, bonding of the polymer-cement concrete was found to be very good even though the strength of the material was low. There was no evidence of debonding on any of the polymer-cement concrete specimens analysed under a microscope. The very low compressive strength of this material, due to the plastic nature, had no negative consequences relating to the durability performance of this material and this is in direct contradiction to the common belief that high strength materials will outperform such materials in non-structural patch repair applications.

Application of the polymer-cement concrete material to substrate concrete was found to be difficult to some extent, relative to conventional repair mortars due to the very sticky nature of a freshly mixed polymer-cement concrete mix. However, the material could still be practically applied to patch repairs. The overall performance of the polymer-cement concrete material was seen to be promising since when considered in isolation, strength does not really matter, neither does shrinkage. The excellent adhesion properties and crack resistance, as well as good durability index results indicate that this material can perform well when fully set.

These results show that patch repair materials should not be assessed based on conventional industry philosophy, which predominantly relates strength to performance. The results exhibited by the $60 \% \mathrm{FA}$ and polymer-cement concrete materials clearly show that such seemingly low-strength materials have the potential 
to outperform high strength repair products. Proprietary repair materials typically claim "superior" properties including high elastic modulus and high compressive strength. However, the use of such materials has not always shown significant improvement in the durability of repaired elements. It is a misconception that repairing corrosion-damaged concrete with such high strength materials will guarantee durability. This approach is principally incorrect and in many cases the use of such materials for non-structural repairs is probably not necessary. Moreover, research conducted at UCT by [3] and [4] has established that high compressive strength materials may actually exhibit poor performance with respect to crack resistance. This is an important finding which identifies that structures repaired with high strength repair materials are unlikely to perform well with respect to long-term durability since they are exposed to cracking which dramatically accelerates the ingress of deleterious substances into concrete.

Apart from researching into new materials, the study presented in this paper also aimed to provide an understanding of the fundamental reasons behind the poor performance of patch repairs. Based on the literature review it was found that a major cause of the poor durability of concrete patch repairs can be attributed to the lack of technical understanding of the substrate-patch system. The theme of compatibility between substrate concrete and patch repair material is frequently mentioned in literature however, in practice compatibility is difficult to achieve. This is because a fresh patch repair material cannot be made to match the properties of older substrate concrete. Moreover, it is a challenge for engineers to select appropriate materials for patch repairs based on the theme of compatibility, particularly when standards based on the principles of compatibility are very limited.

Additionally, the concrete repair industry is saturated with a range of commercially available repair materials which makes it further difficult to select an appropriate material. Also, the long-term durability performance of these materials is not well known. Furthermore, standards such as the EN 1504 typically specify prescriptive requirements of repair materials such as limiting compressive and bond strengths. However, these are usually determined in laboratory conditions and based on the widespread failure of concrete repairs it is clear that these do not relate to actual service conditions. It is important for the concrete repair industry to move towards performance based concrete repairs to ensure long-term durability and service life performance.

There is a need to have a fundamental understanding of the critical material properties actually required of patch-repair materials. An adequate substrate-patch bond and crack resistance are the core requirements of any repair material selected for a patch-repair programme. A seemingly substandard material that meets these principle requirements, such as the polymer-cement concrete material developed in this study, has the potential to outperform specialised repair materials in non-structural applications. The development of alternative and new patch repair materials such as the FA and polymer-cement concrete repair materials, that may not be subjected to the same failure mechanisms as common cementitious material-based repair materials can provide a solution to the large-scale premature failure of concrete patch repairs.

\section{Conclusions}

The study presented in this paper was conducted in an effort to provide an understanding of the fundamental reasons behind the poor performance of patch repairs and develop new and innovative non-structural repair materials that could possibly be used to rehabilitate corrosion damaged concrete structures. This study developed four new repair materials namely: 100\% FA, $80 \%$ FA, $60 \%$ FA and a polymer (with 5\% cement replacement) repair materials. A broad experimental regime was conducted to establish some of the properties of these repair materials and establish whether they could be practically used for non-structural patch repairs. The results from these tests were analysed relative to a control and the following conclusions were drawn out:

- The $60 \%$ FA repair material had the best overall performance however, with an increase in FA content from $60 \%$ to $100 \%$, it was identified that there was a significant drop in overall performance with respect to durability and strength.

- The $80 \%$ FA repair material exhibited borderline performance and therefore, is unlikely to significantly improve the durability of non-structural patch repairs and it will not provide sufficient longterm protection to reinforcement steel particularly, in aggressive environments.

- The $100 \%$ FA repair material was found to exhibit very poor overall performance and it was concluded that the $100 \%$ FA repair material developed in this study is not suitable for any effective application to non-structural patch repairs.

- The overall performance of the polymer-cement concrete material was found to be promising although the material took time to fully set. However, the good adhesion properties of this material as well as excellent crack resistance results indicated that this material can perform well when fully set.

\section{Recommendations}

The following recommendations are made for future studies:

- Investigate into a $70 \%$ FA mix which could also potentially exhibit promising performance.

- Investigate into the use of polymer as an admixture and possibly other admixtures, in the development of a $60 \%$ FA and $70 \%$ FA repair mortar mix in order to establish any improvements in performance with respect to strength, bonding and crack resistance.

- Investigate into polymer-cement concrete mixes with $10 \%, 15 \%, 20 \%$ and $25 \%$ cement replacements since a higher cement content will facilitate the removal of water from the matrix thereby, allowing it to set within a reasonable time frame. 
- The performance of the $60 \%$ FA repair material should be evaluated relative to widely used repair materials to determine its full potential as an effective patch repair material.

- Investigate into the development of a $100 \%$ FA repair mortar using a class $\mathrm{C}$ FA with a different mix design.

- Future studies should look into the long-term corrosion effects of the new materials developed.

\section{References}

1. S. Matthews, I. Holton, J. Morlidge and R. Pool. ConRepNet: a thematic network on performancebased rehabilitation of reinforced concrete structures. Concrete, 37(8) (2003).

2. M.G. Alexander, M.G. \& H.D. Beushausen. Deformation and Volume Change of Hardened Concrete. In Fulton's Concrete Technology. G. Owens, Ed. Ninth ed. Cement and Concrete Institute, South Africa. (2009).
3. H.D. Beushausen, and M. Chilwesa. Assessment and prediction of drying shrinkage cracking in bonded mortar overlays. Cement and Concrete Research, 53, pp. 256-266 (2013).

4. H.D. Beushausen, and N. Bester. The influence of curing on restrained shrinkage cracking of bonded concrete overlays. Cement and Concrete Research, 87, pp.87-96 (2016).

5. Concrete research and structural integrity research unit - CoMSIRU. Durability Index Testing Procedure Manual. Version 2.0. University of Cape Town, (2010).

6. H.D. Beushausenand M. Chilwesa. Assessment and prediction of drying shrinkage cracking in bonded mortar overlays. Cement and Concrete Research, 53, pp. 256-266 (2013).

7. C. Masuku. Tensile relaxation of bonded concrete overlays. Master of Science thesis. Department of Civil Engineering Faculty of Engineering and Built Environment, University of Cape Town. South Africa. (2009). 